\title{
Fabrication of porous ceramics as clay/glass composite
}

\author{
Aleksandrs Korjakins, Liga Radina, Diana Bajare, \\ Riga Technical University, Department of Building Materials and Products \\ Address: Kalku 1, Riga, LV-1658, Latvia.
}

\begin{abstract}
Nowadays porous ceramics are widely researched, becoming an increasingly marketable material in the world, mainly due to the wide possibilities of usage in different technical and technology industries. Porous ceramics are successfully used in the filtration and has a high potential of usage also in the production of heat insulation materials thus obtaining the material which combine high resistance that can compete with other heat insulation and constructive materials.

Article reports a study of porous ceramics, which are produced using foamglass pellets as melting fillers, despite the fact that these additives are not frequently used as filler in traditional ceramic materials. The basis of this method is mixing fire resistant material with hard and melting substance.

For the production of porous ceramics clay, hard filler, water and various sized foamglass pellets were used, thus allowing to determine optimal size of melting filler and thereby ensuring the necessary physical and mechanical properties of the obtained porous ceramic samples and required amount, size and division of pores. Compressive strength tests were performed, as well as density and water absorption of the samples was determined.

Obtained results of the study shows that ceramic materials, obtained within the research, have great potential of application for load-bearing constructions as constructive building materials, as well as insulation materials. Production of porous ceramics materials, where foamglass pellets are used as melting filler, allows to produce more effective ceramics, creating high added value for the final product.
\end{abstract}

Keywords: ecological materials, insulation material, porous ceramics, clay matrix.

\section{INTRODUCTION}

Clay science has emerged after a few millennia of clay use and a century-long accumulation of written information about clays and clay minerals. There are two main features that evoke interest in clays: (1) their common availability, and (2) their extraordinary properties. Clays and clay minerals represent the youngest members of the family of minerals in the Earth's crust, being formed from different parent rocks under variable conditions [1].

Clay allows us to obtain contemporary ceramics, which have more attractive properties compared to metals and polymers, making them useful for specific applications [2], thanks to which it is modern material which can be successfully used from materials of ceramics up to social life, construction and other traditional products of ceramics up to the present time miniature computers, television, cars, planes and spacecraft and other modern technique developments. Current general civilization progress is not conceivable without ceramics [3]. And current material science cannot be imagined without the porous ceramic.
Methods of porous ceramics production are widely studied regarding attaining filtrating ceramics, since this material can be successfully used for the purification of different liquids and gasiform products. Within this subclass, those information and research results allow to apply the knowledge to production of heat-insulation materials because ceramic heatinsulation materials, characterized by high priority, can also be obtained in several ways: using contents of monofraction raw materials, foam formation method, using burn-out additive method and forming of pores in a chemical way.

Within this research, burn-out additive method is used. The basis of this method is mixing fire-resistant material - clay with hard and melting substances chamotte and foamglass pellets, which have not been used as filler in traditional ceramic materials till now.

There are numerous patents on foamglass pellet production dating back to the 1930s. Foamglass was originally manufactured from a specially formulated glass composition, using virgin glass only. Currently, there are number of foamglass production plants that are using up to $98 \%$ post-consumer waste glass in their production. The basic principle of foam glass manufacture is to generate a gas in glass at a 
temperature between $700^{\circ} \mathrm{C}$ to $900^{\circ} \mathrm{C}$. The gas expands thus producing a structure of cells to form a porous body.

Advantages of foamglass are lower transport costs, wide availability. Also foamglass pellets are non-toxic [4].

This study allows us to use unusual filler for production of porous ceramics and compare the obtained results with the properties of the materials, where the traditional fillers were used.

For instance sawdust is traditionally burnable filler used for production of the porous ceramics. It is widely researched both in Latvia by obtaining samples with a strength of $10 \mathrm{MPa}$ to $12 \mathrm{MPa}$ in a density up to $1.5 \mathrm{~g} / \mathrm{cm}^{3}$, by using $25 \%$ woodchip and burning the clay in a $950-960{ }^{\circ} \mathrm{C}$ temperature [5]. The leading Russian scientific centers have developed porous clay ceramic, with compression strength up to $17 \mathrm{MPa}$ [6]. Moreover, mentioned centre's research was conducted to develop a new ceramic based high efficiency heat insulation material with low volume mass of 200-500 $\mathrm{kg} / \mathrm{m}^{3}$ at a processing temperature of $840-960{ }^{\circ} \mathrm{C}$. However, this material exhibited insufficient strength to be used in load-bearing walls [7]. In order to solve the ceramic material strength increase issue, it is being suggested to use e.g. nanotechnologies, thus forming ceramic solid matter nano-crystals. [8].

Besides, nanoscale ceramic powders offer the possibility of manufacturing dense ceramics at low sintering temperature [9].

\section{MATERIALS AND METHODS}

Carbonized clay with volume mass $-1600 \mathrm{~kg} / \mathrm{m}^{3}$ and humidity level of $24 \%$, as well as ground chamotte and water were used for sample preparation, where the various sized foamglass pellets are used as melting filler.

The properties of foamglass pellets are given in Table 1 and the chemical structure of carbonized clay is shown in Table 2.

TABLE 1. PROPERTIES OF FOAMGLASS PELLETS

\begin{tabular}{|l|l|l|}
\hline & \multicolumn{2}{|l|}{ Grain size, $\mathrm{mm}$} \\
\hline Designation & $0-4$ & $4-8$ \\
\hline Bulk density, $\mathrm{kg} / \mathrm{m}^{3}$ & 265 & 150 \\
\hline Volume density, $\mathrm{kg} / \mathrm{m}^{3}$ & 270 & 270 \\
\hline Exploitation regime, ${ }^{\circ} \mathrm{C}$ & \multicolumn{2}{|l|}{ from -250 to +650} \\
\hline
\end{tabular}

TABLE 2. CHEMICAL COMPOSITION OF CLAY

\begin{tabular}{|l|c|c|c|c|c|c|}
\hline Component & $\mathrm{SiO}_{2}$ & $\mathrm{Al}_{2} \mathrm{O}_{3}$ & $\mathrm{Fe}_{2} \mathrm{O}_{3}$ & $\mathrm{MgO}$ & $\mathrm{Na}_{2} \mathrm{O}$ & $\mathrm{MnO}$ \\
\hline Amount, \% & 49.5 & 13.04 & 5.14 & 3.68 & 0.63 & 0.071 \\
\hline Component & $\mathrm{K}_{2} \mathrm{O}$ & $\mathrm{P}_{2} \mathrm{O}_{5}$ & $\mathrm{TiO}_{2}$ & $\mathrm{CaO}$ & $\mathrm{Cr}_{2} \mathrm{O}_{3}$ & $\mathrm{SO}_{3}$ \\
\hline Amount, \% & 3.64 & 0.138 & 0.757 & 8.69 & 0.008 & 0.05 \\
\hline
\end{tabular}

Proportion of dry clay, chamotte and water used in present research varied, changing the amount of chamotte, as well as changing the grain size and amount of foamglass pellets in order to obtain the porous ceramic samples with better mechanical properties.

When making porous ceramics using foamglass pellets as melting filler, components of dry mixture were dosed according to mass, where dried, milled clay was $38-69 \%$, water $-25-37 \%$ but foamglass pellets $6-31 \%$.

Mould at the size $5 \times 5 \mathrm{~cm}$ for sides was used for preparation of the samples.

During the research great attention has been paid to the chemical and mineralogical composition of the carbonized clay, therefore quartz, which reduces the technological characteristics - complicates sintering process, reduces strength and, in certain cases, frost resistance of the samples, has been not used in production of porous ceramics. Quartz also worsens the plasticity of ceramic mass, but reduces the shrinkage of the samples after drying and burning.

Whereas $\mathrm{CaO}$ and $\mathrm{MgO}$ (see Table 2) existing in the clay composition promote sintering of ceramics mass and advancing formation of pores.

\section{Experimental procedure}

In the beginning, clay was dried in the drying oven and ground in RETSCH PM 400 mill for 30 minutes in dry condition. All of the required components were dosed in the required amount and mixed in dry condition, gradually adding water till the sufficiently homogenous mixture for sample making is obtained.

Samples were dried using BINDER FED dryingcase at $70^{\circ} \mathrm{C}$ temperature for 48 hours and afterwards burnt gradually increasing temperature. Within the range of temperature $0^{\circ} \mathrm{C}$ up to $150^{\circ} \mathrm{C}$, samples were kept for 3 hours for the vaporization of excessive water, thus eliminating cracks in the porous ceramic samples. Temperature in the range from $150-800^{\circ} \mathrm{C}$ was increased with rate $5^{\circ} \mathrm{C} / \mathrm{min}$ or $130 \mathrm{~min}$ in total to ensure that melting process of foamglass pellets is not too fast, but in the range from $800-1090^{\circ} \mathrm{C}$ - rate was $2{ }^{\circ} \mathrm{C} / \mathrm{min}$ or $145 \mathrm{~min}$ in total. At the maximal temperature $1090^{\circ} \mathrm{C}$, samples were kept for 2 hours in order to completely burn all of them (see Fig.1). After burning samples were refrigerated for 48 hours by gradual decrease of temperature from $1090^{\circ} \mathrm{C}$ to $20^{\circ} \mathrm{C}$.

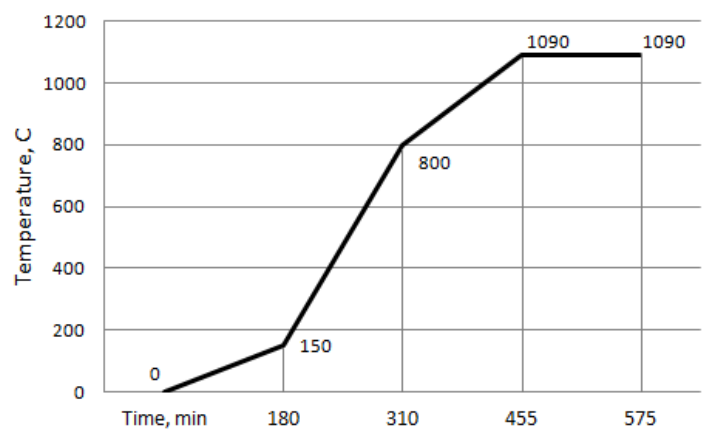

Fig. 1. Sample burning graph 
Water absorption, volumetric mass, compressive strength, as well as an efficiency coefficient $C_{E}$ has been defined for the obtained porous ceramic samples, using the following equation:

$$
\mathrm{C}_{\mathrm{E}}=\mathrm{Rcs} / \rho \mathrm{cs} * 100
$$

Where Rcs - Compressive strength, MPa. pcs - Volume density, $\mathrm{kg} / \mathrm{m}^{3}$

\section{RESULTS AND DISCUSSION}

The goal of this research is to obtain a porous ceramic materials with definite volume density and compressive strength characteristics, so achieving a material that could be used for load-bearing constructions as constructive building material, as well as insulation material.

To achieve the goal of the research, it was necessary to select the composition of formation mixture, drying and burning regimes, as well as determine the mechanical and structural parameters of ceramic samples, selecting the best possible composition of the drying/burning regimes and composition.

Volumetric mass of samples where foamglass pellets with grain size of $4-8 \mathrm{~mm}$ were used as the melting filler, varied from $861.71 \mathrm{~kg} / \mathrm{m}^{3}$, if the amount of filler is $18 \%$, to $1178.34 \mathrm{~kg} / \mathrm{m}^{3}$, if the amount of filler is $6 \%$ (Fig. 2).

While the volumetric mass of samples where foamglass pellets with grain size of $0-4 \mathrm{~mm}$ were used, varied from $1094,03 \mathrm{~kg} / \mathrm{m}^{3}$, if the amount of filler is $20 \%$, to $1472,01 \mathrm{~kg} / \mathrm{m}^{3}$, if the amount of filler is $35 \%$ (Fig. 2).

Grain size, mm; amount of filler, \%; amount of water, $\%$

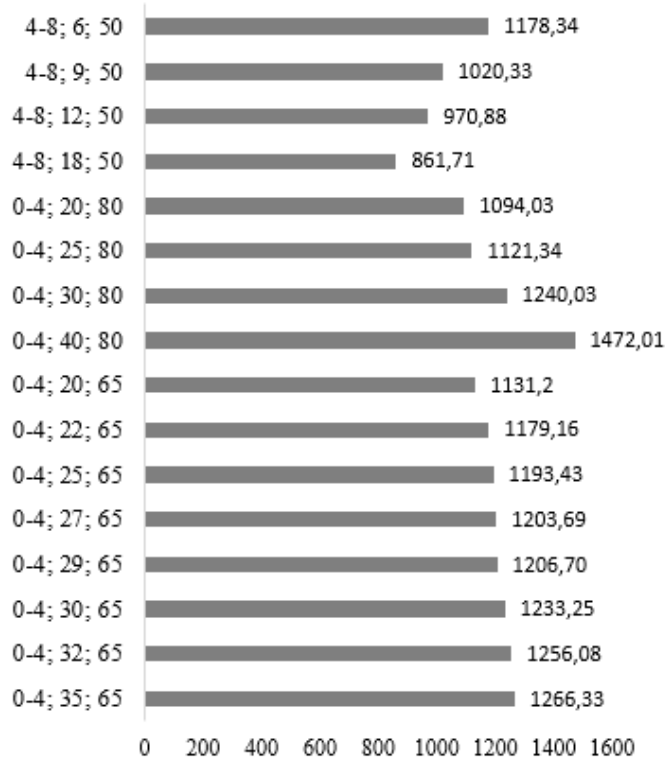

Fig. 2. Average volumetric mass of the samples with grain size of $0-4 \mathrm{~mm}$ and $4-8 \mathrm{~mm}$
For the preparation of samples, using 0-4 $\mathrm{mm}$ foamglass pellets, the necessary water amount was higher $(65-80 \%$ comparing to the amount of dried clay) in comparison to samples where the grain size of foamglass pellets was $4-8 \mathrm{~mm}$, in order to ensure a better consistency of the mixture and increase the amount of melting filler.

Despite the fact, that samples, where the smaller filler (0-4 mm) was used, were with higher volume density, usage of smaller grain size made it possible to avoid the formation of cracks in the material after the drying and burning of samples.

Shrinkage of the samples was measured after their drying and after burning. For samples with foamglass grain size of $4-8 \mathrm{~mm}$ was from $2.22 \%$ up to $8.78 \%$. Highest shrinkage was observed at the freater amount of filler.

Shrinkage of samples with foamglass grain size of $0-4 \mathrm{~mm}$ was from $3.27 \%$ up to $15.02 \%$, increasing if the amount of filler is higher.

Shrinkage after the burning of samples, where the foamglass pellets with grain size of $4-8 \mathrm{~mm}$ were used, was from 3.33 to $11.56 \%$, but for samples with foamglass grain size of $0-4 \%-15.27-28.12 \%$; in both cases the least shrinkage was observed for the samples smaller content of the melting filler.

Compressive strength was determined for all the samples, the resulting values for the samples with foamglass grain size of $4-8 \mathrm{~mm}$ can be seen in Fig.3, whereas resulting values for the samples with grain size of 0-4 mm are summarized in Fig.4.

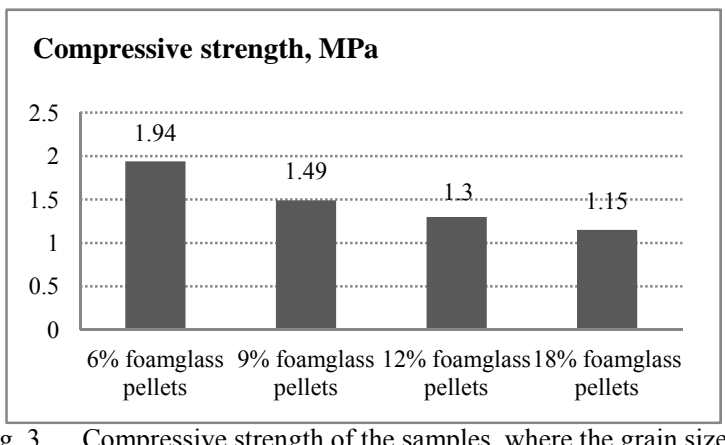

Fig. 3. Compressive strength of the samples, where the grain size of foamglass pellets is $4-8 \mathrm{~mm}$

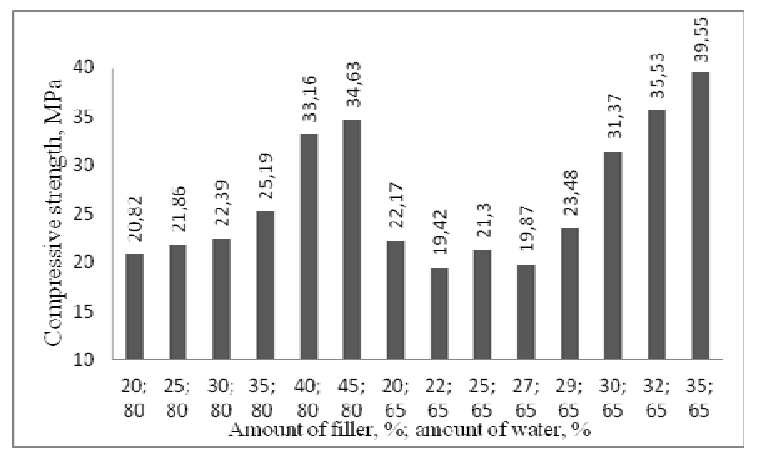

Fig. 4. Compressive strength of the samples, where the grain size of foamglass pellets is $0-4 \mathrm{~mm}$ 
Greatest compressive strength $-39.55 \mathrm{MPa}$ has been stated for the samples with $65 \%$ of water, where $35 \%$ of foamglass pellets with grain size of $0-4 \mathrm{~mm}$ were used as a melting filler. For the samples with the foamglass grain size of $0-4 \mathrm{~mm}$ and $80 \%$ water amount the greatest compressive strength, using $45 \%$ of filler, reached $34.63 \mathrm{MPa}$. Greatest compressive strength in both cases was observed for samples with highest content of foamglass pellets.

In samples where foamglass pellets with grain size 4-8 $\mathrm{mm}$ were used the compressive strength is in range from $1.15 \mathrm{MPa}$ to $1.94 \mathrm{MPa}$ by respective increase upon decreasing of the amount of melting filler.

Water absorption of the samples, where the grain size of melting filler is $0-4 \mathrm{~mm}$ or $4-8 \mathrm{~mm}$ was obtained during the research it is summarized in Table 3.

TABLE 3. WATER ABSORPTION OF THE SAMPLES

\begin{tabular}{|l|l|l|l|}
\hline $\begin{array}{c}\text { Grain size } \\
\text { of filler, } \\
\mathrm{mm}\end{array}$ & $\begin{array}{c}\text { Amount of } \\
\text { filler, } \\
\%\end{array}$ & $\begin{array}{c}\text { Amount of } \\
\text { water, } \\
\%\end{array}$ & $\begin{array}{c}\text { Water } \\
\text { absorption, } \\
\%\end{array}$ \\
\hline $4-8$ & 6 & 50 & 10.21 \\
\hline $4-8$ & 9 & 50 & 9.55 \\
\hline $4-8$ & 12 & 50 & 9.11 \\
\hline $4-8$ & 18 & 50 & 8.33 \\
\hline $0-4$ & 20 & 80 & 6.52 \\
\hline $0-4$ & 25 & 80 & 4.53 \\
\hline $0-4$ & 30 & 80 & 3.51 \\
\hline $0-4$ & 40 & 80 & 2.70 \\
\hline $0-4$ & 20 & 65 & 6.78. \\
\hline $0-4$ & 22 & 65 & 5.71 \\
\hline $0-4$ & 25 & 65 & 5.70 \\
\hline $0-4$ & 27 & 65 & 4.53 \\
\hline $0-4$ & 29 & 65 & 4.48 \\
\hline $0-4$ & 30 & 65 & 4.09 \\
\hline $0-4$ & 32 & 65 & 3.72 \\
\hline $0-4$ & 35 & 65 & 2.65 \\
\hline
\end{tabular}

Obtained data demonstrates that the greatest water absorption $-10.21 \%$ is for the samples with filler grain size of 4-8 $\mathrm{mm}$ and the amount of filler $-6 \%$.

Water absorption of samples, where the grain size of filler is $0-4 \mathrm{~mm}$ varies from $2.65 \%$ for samples with $65 \%$ of water and $35 \%$ of filler to $6.78 \%$ for samples with $65 \%$ of water and $20 \%$ of foamglass pellets.

For grain size of $0-4 \mathrm{~mm}$ and $4-8 \mathrm{~mm}$ the greater water absorption is recognized for the samples with smaller content of the melting filler.

Efficiency (as a proportion between the compressive strength and volume density) has been defined (Table 4) for the obtained porous ceramic samples in order to better characterization of the interdependence of the material properties. Samples with the $4-8 \mathrm{~mm}$ foamglass pellets are $10.31-24.00$ times less effective comparing to samples where the grain size of foamglass pellets is $0-4 \mathrm{~mm}$, reaching from $0.13-0.16$ of efficiency.

\begin{tabular}{|c|c|c|c|c|c|}
\hline $\begin{array}{c}\text { Grain } \\
\text { size } \\
\text { of } \\
\text { filler, } \\
\mathrm{mm}\end{array}$ & $\begin{array}{c}\text { Amou } \\
\text { nt of } \\
\text { filler, } \\
\%\end{array}$ & $\begin{array}{c}\text { Amoun } \\
\text { t of } \\
\text { water, } \\
\%\end{array}$ & $\begin{array}{l}\text { Volum. } \\
\text { mass, } \\
\mathrm{kg} / \mathrm{m}^{3}\end{array}$ & $\begin{array}{l}\text { Compr. } \\
\text { strength, } \\
\mathrm{MPa}\end{array}$ & $\begin{array}{c}\text { Efficie } \\
\text { ncy, }\end{array}$ \\
\hline $4-8$ & 6 & 50 & 1178.34 & 1.94 & 0.16 \\
\hline $4-8$ & 9 & 50 & 1020.33 & 1.49 & 0.15 \\
\hline $4-8$ & 12 & 50 & 970.88 & 1.30 & 0.14 \\
\hline $4-8$ & 18 & 50 & 861.71 & 1.15 & 0.13 \\
\hline $0-4$ & 20 & 80 & 1094.03 & 20.82 & 1.90 \\
\hline $0-4$ & 25 & 80 & 1121.34 & 21.86 & 1.95 \\
\hline $0-4$ & 30 & 80 & 1240.03 & 22.39 & 1.81 \\
\hline $0-4$ & 40 & 80 & 1472.01 & 33.16 & 2.25 \\
\hline $0-4$ & 20 & 65 & 1131.20 & 22.17 & 1.96 \\
\hline $0-4$ & 22 & 65 & 1179.16 & 19.42 & 1.65 \\
\hline $0-4$ & 25 & 65 & 1193.43 & 21.30 & 1.78 \\
\hline $0-4$ & 27 & 65 & 1203.69 & 19.87 & 1.65 \\
\hline $0-4$ & 29 & 65 & 1206.70 & 23.48 & 1.95 \\
\hline $0-4$ & 30 & 65 & 1233.25 & 31.37 & 2.54 \\
\hline $0-4$ & 32 & 65 & 1256.08 & 35.53 & 2.83 \\
\hline $0-4$ & 35 & 65 & 1266.33 & 39.55 & 3.12 \\
\hline
\end{tabular}

Maximal efficiency of the samples is 3.12, if the amount of filler is $35 \%$ and the amount of water is $65 \%$. It can be seen that highest efficiency is observed at greater amount of filler and lower amount of water.

Macropores and micropores can be seen within the structure of porous ceramic sample, where melting filler grain size was $0-4 \mathrm{~mm}$. Pores, acquired by melting of foamglass pellets, have regular form and pores measuring $0.2-1.5 \mathrm{~mm}$ as they are shown in Fig. 5.

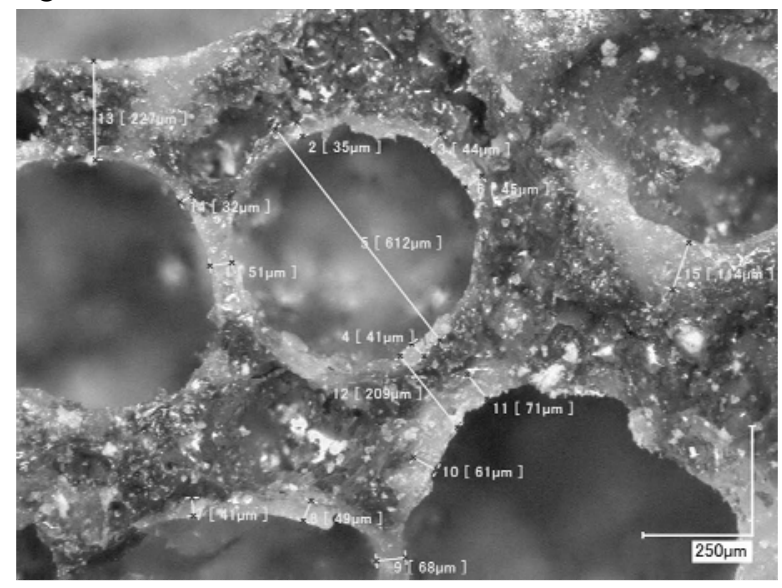

Fig. 5. Micrography of porous ceramic, where the grain size of melting filler was $0-4 \mathrm{~mm}$.

It can be seen in micrography, that after the melting of foamglass pellets, $0.04-0.11 \mathrm{~mm}$ thick glass layer ir formed around the pores, providing samples with higher compressive strength and lower water absorption. 


\section{Discussion}

During the research the acquisition of porous ceramics was practically demonstrated by using foamglass pellets with different grain size as the melting filler upon changing the amount of it and obtaining the material with various physical and mechanical features.

Volumetric mass of porous ceramic samples can be easily regulated by changing the amount and type of foamglass pellets, if the amount of water is kept at the same level, as well as changing the necessary amount of water. With the lower amount of water, plasticity of the mixture decreases and it is more difficult to get homogeneous mixture as well as to work it in the moulds, though besides the decrease of plasticity we must also consider the increase of compressive strength and efficiency, therefore recognition and acquisition of optimal proportion between the mentioned parameters plays essential role, thus ensuring the acquisition of optimal material.

Obtained results of the research testify that porous ceramics, obtained within this research, have a great potential of application for load-bearing constructions.

Decreasing of water absorption with increasing amount of melting filler - foamglass pellets in ceramics may be explained by decreasing permeability of the materials for water due to covering inner surface of voids by glass (Fig. 5). It means that the obtained material should improve the thermal insulation properties by saving breathing possibility.

In line with the conducted research, the addition of foamglass pellets as a melting filler improves the strength of the obtained samples, however, it reduces the temperature necessary for burning as well as the amount of clay required, thus enabling to save a natural resources through effective recycling of the glass waste.

With the use of mentioned porous ceramic production method, heat insulation elements of various forms (depends on moulds) and sizes may be obtained, controlling the size and amount of pores in the material.

The following investigation will be devoted to developing more effective material by controlling thermal conductivity properties.

\section{CONCLUSION}

Within the research samples of porous ceramics were developed upon application of melting fillers with various grain size, stating the shrinkage (after the artificial drying and burning), volumetric mass, water absorption, compressive strength and efficiency (as a ratio between compressive strength and volumetric mass) of the acquired samples.

Following results were obtained for the samples, where the grain size of the melting filler was $4-8 \mathrm{~mm}$ : volumetric mass $-861.71 \mathrm{~kg} / \mathrm{m}^{3}$, if the amount of filler is $18 \%$, to $1178.34 \mathrm{~kg} / \mathrm{m}^{3}$, if the amount of filler is
$6 \%$; shrinkage after drying - from $2.22 \%$ up to $8.78 \%$ and the highest shrinkage was recognized at the greater amount of filler; shrinkage after burning - from 3.33 to $11.56 \%$, compressive strength -1.15 to 1.94 $\mathrm{MPa}$, water absorption - 8.33 - $10.21 \%$ and efficiency $-0.13-0.16$.

While for the samples, where the grain size of the melting filler was $0-4 \mathrm{~mm}$ volumetric mass varied from $1094,03 \mathrm{~kg} / \mathrm{m}^{3}$, if the amount of filler is $20 \%$, to $1472,01 \mathrm{~kg} / \mathrm{m}^{3}$, if the amount of filler is $35 \%$, shrinkage after drying - from $3.27 \%$ up to $15.02 \%$, increasing if the amount of filler is higher, shrinkage after burning - 15.27-28.12\%; compressive strength 19.42 $\mathrm{MPa}$ to $39,55 \mathrm{MPa}$, which has been stated for the samples with $65 \%$ of water, where $35 \%$ of foamglass pellets were used as a melting filler. For the samples with $80 \%$ water amount the greatest compressive strength, using $45 \%$ of filler, reached $34.63 \mathrm{MPa}$. Highest compressive strength in both cases was observed for samples with highest content of foamglass pellets. Water absorption of the samples - from $2.65 \%$ for samples with $65 \%$ of water and $35 \%$ of filler to $6.78 \%$ for samples with $65 \%$ of water and $20 \%$ of foamglass pellets. Efficiency $-1.65-3.12 \%$, where greatest efficiency is observed at greater amount of filler and lower amount of water.

By comparing the features of the obtained materials we can see that samples, where the grain size of melting filler is $0-4 \mathrm{~mm}$ have better compressive strength, efficiency and water absorption indicators, but samples, where the grain size of filler is 4-8 $\mathrm{mm}-$ lower volumetric mass. It can be seen, that, despite the decrease of the mixture plasticity, the usage of smaller amount of water $-65 \%$ instead of $80 \%$, guarantees better properties of the material, as well as reduces the amount of melting filler, which we can use, therefore fot the acquisition of necessary features of the material, in the following researches it is essential to find the optimal amount of filler and water.

Production of porous ceramics materials where foamglass pellets are used as the melting filler, allows us to create more effective ceramics, using waste glass and creating high added value for the final product.

\section{ACKNOWLEDGMENTS}

The financial support of the Latvian Council of Science, project Nr.12.0412 is acknowledged.

\section{REFERENCES}

[1] F. Bergaya, B.K.G. Theng, G. Lagaly, Handbook of clay science. Amsterdan, The Netherlands: Elsevier Academic Press , 2006, p. 19.

[2] G. Sedmale, Keramika. Ķīmija un tehnologija. Rīga, RTU izdevniecība, 2010, pp. 224-225.

[3] S. El-Haggar, Sustainable industrial design and waste management. Burlington, MA: Elsevier Academic Press, 2007, pp. 175-177.

[4] D. Munz, T. Fett, Ceramics. Mechanical Properties, Failure Behaviour, Materials Selection. Springer - Verlag Berlin Heidelberg New York, 1999, pp. 1-2. 
[5] G. Sedmale, A. Cimmers, .U. Sedmalis, Charasteristics of illite clay and compositions for porous building ceramics production. Instiute of Silicate Materials, Riga Technical University, Chemine Technologija Vol. 2. 2009, p.51.

[6] A. Salahov, L. Tagirov, R. SalahovaV. Parfenov, N. Ljadov, Поры и прочностные характеристики строительных материалов. Строительные материалы, Vol. 12. 2011, pp. 25-27.

[7] M. Amamchan, Технология получения теплоизоляиионного материала на основе легкоплавких глин. Строительные материалы, Vol. 8. 2009, pp.68-69.
[8] A. Salahov, A. Livada, R. Salahova, Нанотехнология гарантия заданных свойств керамических материалов. Строительные материалы, Vol 4. 2008, pp. 27-29.Vile M.A., Wieder R.K. and Novak M. Mobility of $\mathrm{Pb}$ in Sphagnumderived peat. Biochemistry 45. 1999, pp. 35-52.

[9] K. A. Khalil, Advanced Sintering of Nano-Ceramic Materials. Ceramic Materials - Progress in Modern Ceramics, InTech. 2012, p.66. 